\title{
Anterior corpectomy via the mini-open, extreme lateral, transpsoas approach combined with short-segment posterior fixation for single-level traumatic lumbar burst fractures: analysis of health-related quality of life outcomes and patient satisfaction
}

\author{
Alexander A. Theologis, MD, Ehsan Tabaraee, MD, Paul Toogood, MD, Abbey Kennedy, MD, \\ Harjus Birk, BS, R. Trigg McClellan, MD, and Murat Pekmezci, MD \\ Department of Orthopaedic Surgery, University of California, San Francisco General Hospital, San Francisco, California
}

\begin{abstract}
OBJECTIVE The authors present clinical outcome data and satisfaction of patients who underwent minimally invasive vertebral body corpectomy and cage placement via a mini-open, extreme lateral, transpsoas approach and posterior short-segment instrumentation for lumbar burst fractures.

METHODS Patients with unstable lumbar burst fractures who underwent corpectomy and anterior column reconstruction via a mini-open, extreme lateral, transpsoas approach with short-segment posterior fixation were reviewed retrospectively. Demographic information, operative parameters, perioperative radiographic measurements, and complications were analyzed. Patient-reported outcome instruments (Oswestry Disability Index [ODI], 12-Item Short Form Health Survey [SF-12]) and an anterior scar-specific patient satisfaction questionnaire were recorded at the latest follow-up.

RESULTS Twelve patients ( 7 men, 5 women, average age 42 years, range 22-68 years) met the inclusion criteria. Lumbar corpectomies with anterior column support were performed (L-1, $n=8 ; L-2, n=2 ; L-3, n=2)$ and supplemented with short-segment posterior instrumentation (4 open, 8 percutaneous). Four patients had preoperative neurological deficits, all of which improved after surgery. No new neurological complications were noted. The anterior incision on average was $6.4 \mathrm{~cm}$ (range $5-8 \mathrm{~cm}$ ) in length, caused mild pain and disability, and was aesthetically acceptable to the large majority of patients. Three patients required chest tube placement for pleural violation, and 1 patient required reoperation for cage subsidence/hardware failure. Average clinical follow-up was 38 months (range 16-68 months), and average radiographic follow-up was 37 months (range 6-68 months). Preoperative lumbar lordosis and focal lordosis were significantly improved/maintained after surgery. Patients were satisfied with their outcomes, had minimal/moderate disability (average ODI score 20, range $0-52$ ), and had good physical (SF-12 physical component score $41.7 \% \pm 10.4 \%$ ) and mental health outcomes (SF-12 mental component score $50.2 \% \pm 11.6 \%$ ) after surgery.
\end{abstract}

CONCLUSIONS Anterior corpectomy and cage placement via a mini-open, extreme lateral, transpsoas approach supplemented by short-segment posterior instrumentation is a safe, effective alternative to conventional approaches in the treatment of single-level unstable burst fractures and is associated with excellent functional outcomes and patient satisfaction.

http://thejns.org/doi/abs/10.3171/2015.4.SPINE14944

KEY WORDS corpectomy; burst fractures; extreme lateral; transpsoas approach; minimally invasive surgery; clinical outcomes; lumbar; trauma

$\mathrm{T}$ Raditional open anterior approaches to the lumbar spine are associated with significant morbidity. ${ }^{12}$ Complications associated with open anterior approaches include major vascular injury, pulmonary embo- lism, postoperative ileus, retrograde ejaculation, incisional hernias, and superficial and deep wound infections. ${ }^{12}$ Thus, the use of less-invasive and alternative anterior approaches to the lumbar spine has gained popularity. Ozgur et al. first

ABBREVIATIONS ASA = American Society of Anesthesiologists; MCS = mental component score; MIS = minimally invasive surgery; ODI = Oswestry Disability Index; PCS = physical component score; SF-12 = 12-Item Short Form Health Survey; TLICS = Thoracolumbar Injury and Classification Score.

SUBMITTED September 16, 2014. ACCEPTED April 10, 2015.

INCLUDE WHEN CITING Published online October 2, 2015; DOI: 10.3171/2015.4.SPINE14944. 
described the effectiveness and safety of the mini-open, extreme lateral, transpsoas approach for access to the lumbar interbody space. ${ }^{18}$ Since this initial report, the transpsoas approach for interbody fusion has shown promising results with few complications in patients with or without deformity. ${ }^{10,23}$ Reports that detail the use of the transpsoas approach for anterior stabilization with corpectomy and cage placement for the treatment of unstable lumbar burst fractures are numerous, , 1,2,6-8,13,16,20,24 albeit none report postoperative health-related quality of life measures or assess patient satisfaction after the operation. Thus, the purpose of this study was to present the satisfaction and clinical outcomes of patients with a single-level, unstable, traumatic burst fracture treated with corpectomy and cage placement via a mini-open, extreme lateral, transpsoas approach and posterior short-segment fixation.

\section{Methods}

The institutional review board at our institution approved this study. Adults who underwent single-level lumbar corpectomies, cage placement through a mini-open, extreme lateral, transpsoas approach, and short-segment posterior instrumentation between June 2009 and July 2013 were retrospectively reviewed. Surgical indications included the presence of neurological symptoms, posterior ligamentous complex disruption, and progressive loss of vertebral height or increased vertebral kyphosis, or both, noted on standing radiographs in a thoracolumbosacral orthosis. ${ }^{15}$ A Thoracolumbar Injury and Classification Score (TLICS) was calculated: a score greater than or equal to 4 was used as an indication for surgical fixation. When a neurological deficit was not present, the load-sharing classification score was calculated to evaluate the need for anterior column support following shortsegment posterior instrumentation. ${ }^{14} \mathrm{~A}$ score greater than 6 was an indication for anterior column support. ${ }^{14}$ Open posterior instrumentation and fusion was performed if a patient had a neurological deficit or a vertical lamina fracture (greenstick fracture). In this scenario, the posterior approach was performed before the anterior column decompression and cage placement to decompress the neural elements, evaluate for nerve root entrapment or dural tear, or both. ${ }^{3,19}$ In patients without a greenstick fracture or a neurological deficit, posterior instrumentation by a percutaneous method (described below) was performed. Clinical data included patient age, sex, medical comorbidities, American Society of Anesthesiologists (ASA) classification, TLICS, associated injuries, perioperative neurological function, length of operation, incision length, intraoperative blood loss, need for chest tube placement and blood transfusions, postoperative complications, length of hospital stay, disposition, and need for revision surgery. Preoperative, first postoperative, and latest follow-up radiographs were analyzed. The surgeon who performed the operation evaluated all radiographs. CT scans were not routinely obtained on each patient to evaluate fusions, given concerns of cost and radiation to patients. For patients who did not receive a postoperative CT scan, maintenance of hardware alignment and nonsignificant implant settling or deformity were used as proxies for union. Radiographic data included focal lordosis (defined as the angle between the endplates of the vertebra above and below the level of the fracture) and lumbar lordosis (defined as the angle between the S-1 endplate and the L-1 endplate). Pre- and postoperative radiographic parameters were compared with each other using a 2-tailed Student t-test. A p value < 0.05 was considered statistically significant.

\section{Health-Related Quality of Life and Patient Satisfaction Assessment}

One year after treatment, patients were called and asked to return to the clinic for radiographic and clinical follow-up. If they were not able to return to clinic, they were asked over the phone to answer questions from the Oswestry Disability Index (ODI), ${ }^{9}$ 12-Item Short Form Health Survey (SF-12) questionnaire, ${ }^{22}$ and a specific scar-related questionnaire, as previously reported by Kim et al. ${ }^{12}$ The ODI is one of the principle condition-specific outcome measures for patients with low-back pain, which includes 10 questions that attempt to gauge the effect of back or leg pain on a patient's ability to perform activities of daily living. All ODI scores were added, producing a $0 \%-100 \%$ scale, with $0 \%-20 \%$ representing minimal disability, 20\%-40\% representing moderate disability, $40 \%-60 \%$ representing severe disability, $60 \%-80 \%$ representing a "crippled" state, and 80\%-100\% representing a bed-bound patient or one who is exaggerating his or her symptoms. The SF-12 form consists of 12 questions and measures overall functional health and well-being. Two scores, the physical component score (PCS) and mental component score (MCS), are derived from the questionnaire and provide information regarding the physical and mental well being of an individual, respectively. The scarrelated questionnaire is composed of questions related to the patient's pain, appearance, bulging, daily life with respect to their scar, and satisfaction with surgery. ${ }^{12}$

\section{Surgical Technique}

The patient is brought to the operating room and intubated. Dose-appropriate antibiotics are administered preoperatively. If the patient is to undergo both an anterior corpectomy and posterior instrumentation, he or she is then placed prone on a Jackson table in preparation for the posterior instrumentation.

\section{Posterior Instrumentation: Open Versus Percutaneous}

Patients with a greenstick lamina fracture, a neurological deficit, or both, undergo standard posterior instrumentation and fusion. In the absence of these findings, percutaneous pedicle screw instrumentation is performed using the following technique. The operative level is localized under fluoroscopy and Jamshidi needles are used to cannulate the pedicles 1 level above and below the fracture under fluoroscopy with a standard kyphoplasty technique. Guidewires are placed through the needles, followed by sequential dilators. Appropriately sized pedicle screws are placed over the guidewires under fluoroscopic guidance. Finally, appropriate-length rods are placed below the fascia. Because the patients are placed on the Jackson table, a significant amount of reduction is achieved with position- 
ing. To achieve more reduction, a hyperlordosing force is applied through the posterior elements just before the set of screws are tightened.

\section{Single-Level Corpectomy via a Mini-Open, Extreme Lateral, Transpsoas Approach}

The patient is in the right lateral decubitus position on the standard operating table. The level of the fracture is localized on the left flank using fluoroscopy. A minimally invasive incision is made over the previously marked area of injury. The dissection is first carried down to the level of the rib, after which the periosteum is incised and a portion of the rib is excised. A retropleural/retroperitoneal dissection is extended down to the level of the injured vertebral body. The MaXcess retractor instrumentation (Nuvasive) is subsequently used. Neuromonitoring probes are placed to check the position of the lumbar plexus. Once the position of the dilators are confirmed, retractors are placed within the incision, and their positions are checked with fluoroscopy. The retractors are opened and the injured vertebral bodies as well as the disc above and below are exposed. The position of the plexus is once again checked with the neuromonitoring probe. The portion of the psoas muscle overlying the injured vertebral body is subsequently released, and the segmental artery is ligated. The discs caudal and cephalad to the injured vertebra are first removed using a disc knife and box osteotome. Osteotomes are used to remove the central portion of the vertebral body, which is saved for autograft for later use. The anterior vertebral wall is left intact. The posterior vertebral wall is also left intact, unless the patient has preoperative neurological deficits. Based on the size of the vertebra and local angulation, the height of the cages and size and angulation of the footplates are measured. The cage is packed with autograft that was previously harvested from the vertebral body and is inserted at the corpectomy site. No allograft, bone substitutes, or bone morphogenetic protein were used. Fluoroscopy is then used to confirm the position of the cage. A chest tube is placed if the pleura is violated. This is not an uncommon event, particularly at higher levels (i.e., L-1). The wound is thoroughly irrigated and closed in separate layers.

\section{Results}

Twelve patients $(7$ men, 5 women, average age 42 years, range 22-68 years) met inclusion criteria (Table 1). The average ASA score was 1.7 (range 1-3) and average TLICS score was 5 (range 4-8). Four patients had preoperative neurological deficits. Case 2 (Table 1) had an L-3 burst fracture with bilateral radicular pain in the L-3 nerve root distributions. At her 61-month postoperative visit, she was neurologically intact. Case 9 (Table 1) was initially neurologically intact, but developed urinary retention and bilateral lower extremity paresthesias after weight bearing in a brace. Because upright radiographs demonstrated progressive kyphosis and an MRI demonstrated no evidence of posterior osseous fracture or posterior compression, she underwent posterior percutaneous instrumentation and an L-1 anterior corpectomy with cage placement. Postoperatively, her urinary retention and paresthesias resolved before discharge from the hospital. Case 11 (Table 1) presented with cauda equina symptoms, including urinary and bowel incontinence, $4 / 5$ strength in the left lower extremity, and 3/5 strength in the right lower extremity. While her bowel and bladder symptoms and left lower extremity weakness resolved after she underwent an open T12-L2 posterior spinal fusion with L-1 laminectomy followed by an L-1 anterior corpectomy, her right lower extremity weakness was not improved at 18 -month follow-up. Case 12 (Table 1) had an L-1 burst fracture and cauda equina (3/5 strength in bilateral lower extremities). He underwent an open T12-L2 posterior spinal fusion and L-1 laminectomy followed by an anterior L-1 corpectomy. At 18-months follow-up, he was neurologically intact.

Three patients sustained multiple injuries. The first patient (Case 8) sustained right femur, left tibia, right humerus, T-8, T-10, and L-5 compression fractures, and an epidural hematoma that did not require surgical intervention. The second polytrauma patient (Case 11) sustained an open right tibial plafond and right calcaneus fractures. The third polytrauma patient (Case 12) sustained a right pneumothorax, bilateral open tibial plafond, right calcaneus, sternal, and bilateral rib fractures. Eight of the fractures were at L-1, 2 fractures were at L-2, and 2 fractures were at L-3. The average time to surgery was 5.9 days (range 0-24 days). Procedural details are outlined in Table 1. An open posterior approach was performed in 4 patients for lamina greenstick fractures (Cases 2 and 3) or neurological deficits (Cases 2, 11, and 12), or both. Eight patients without a lamina fracture or neurological deficit underwent percutaneous posterior instrumentation. Anterior instrumentation was accomplished with either an expandable cage that had traditional "circular" footprints (Fig. 1; $\mathrm{n}=4$ ) or with a wide "rectangular" footprint (Fig. $2 ; n=8)$. Intraoperative and hospital data are summarized in Table 2. Of note, the incision length for all patients was less than 8 centimeters (Table 2).

Three main postoperative complications occurred (Table 1), 1 of which was related to the anterior approach of the procedure. One patient (Case 2) was a 68-year-old woman with osteoporosis who experienced cage subsidence with fracture of the upper endplate that resulted in progressive loss of fixation (Fig. 1). A circular footplate was used for her anterior stabilization. She underwent revision surgery, which included a T12-L5 posterior spinal fusion with an L-2 kyphoplasty (Fig. 1). The second patient (Case 3) was diagnosed with a deep wound infection (methicillin sensitive Staphylococcus aureus) of his posterior spinal hardware a month after the index procedure. The instrumentation was retained after the irrigation and debridement. The patient was successfully treated with 6 weeks of intravenous antibiotics and oral suppression for 1 year. This patient had no complications related to his anterior approach. The last patient (Case 5) experienced a pulmonary embolism on postoperative day 2 , which was treated with standard anticoagulation without further complications. The majority of patients were discharged home (Table 2), and all but 1 patient's hospital stay was less than 3 weeks in duration (Table 2). The aforementioned polytrauma patients had an inpatient stay of 47 days, 20 days, and 42 days, respectively. 


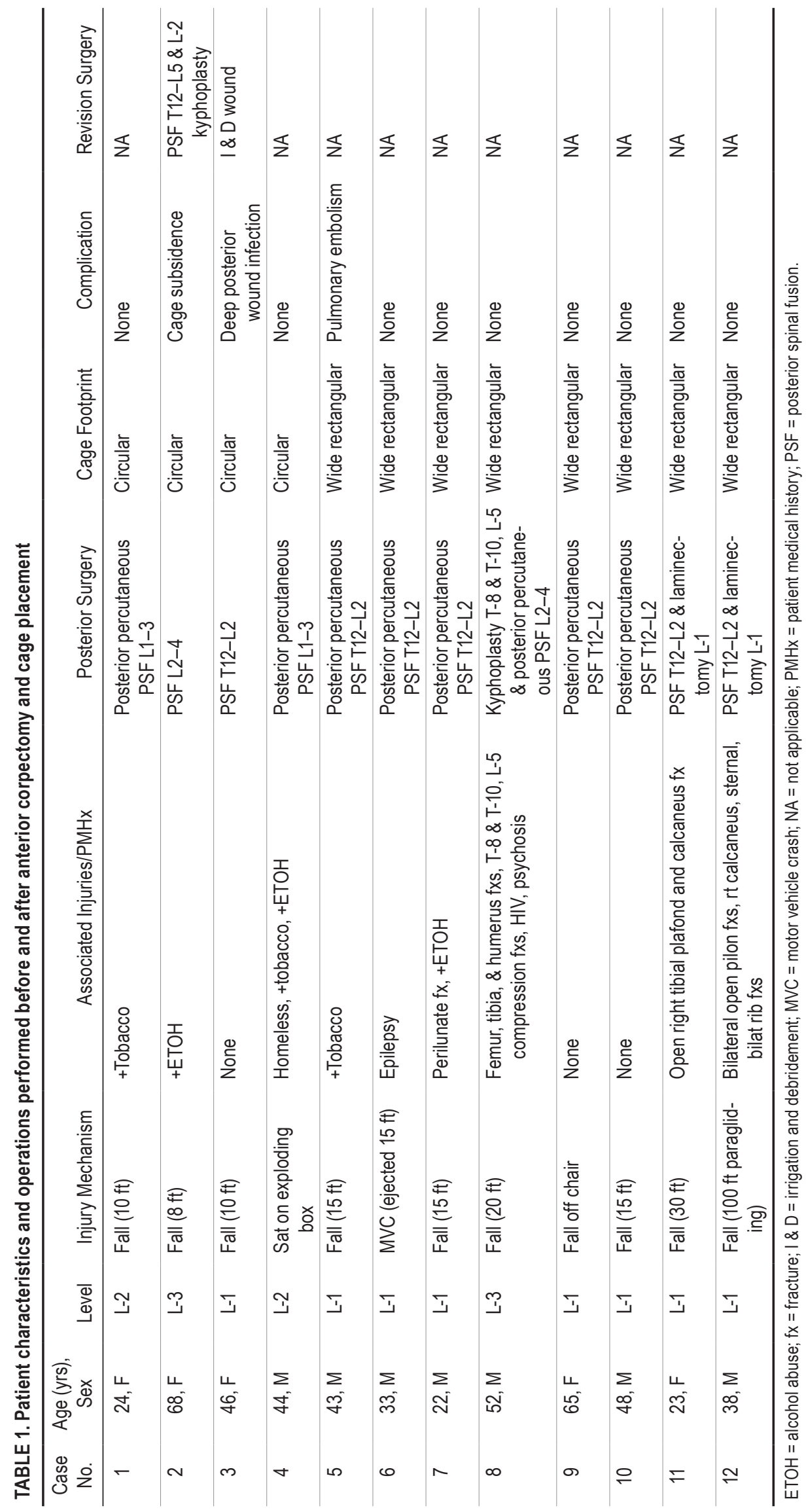



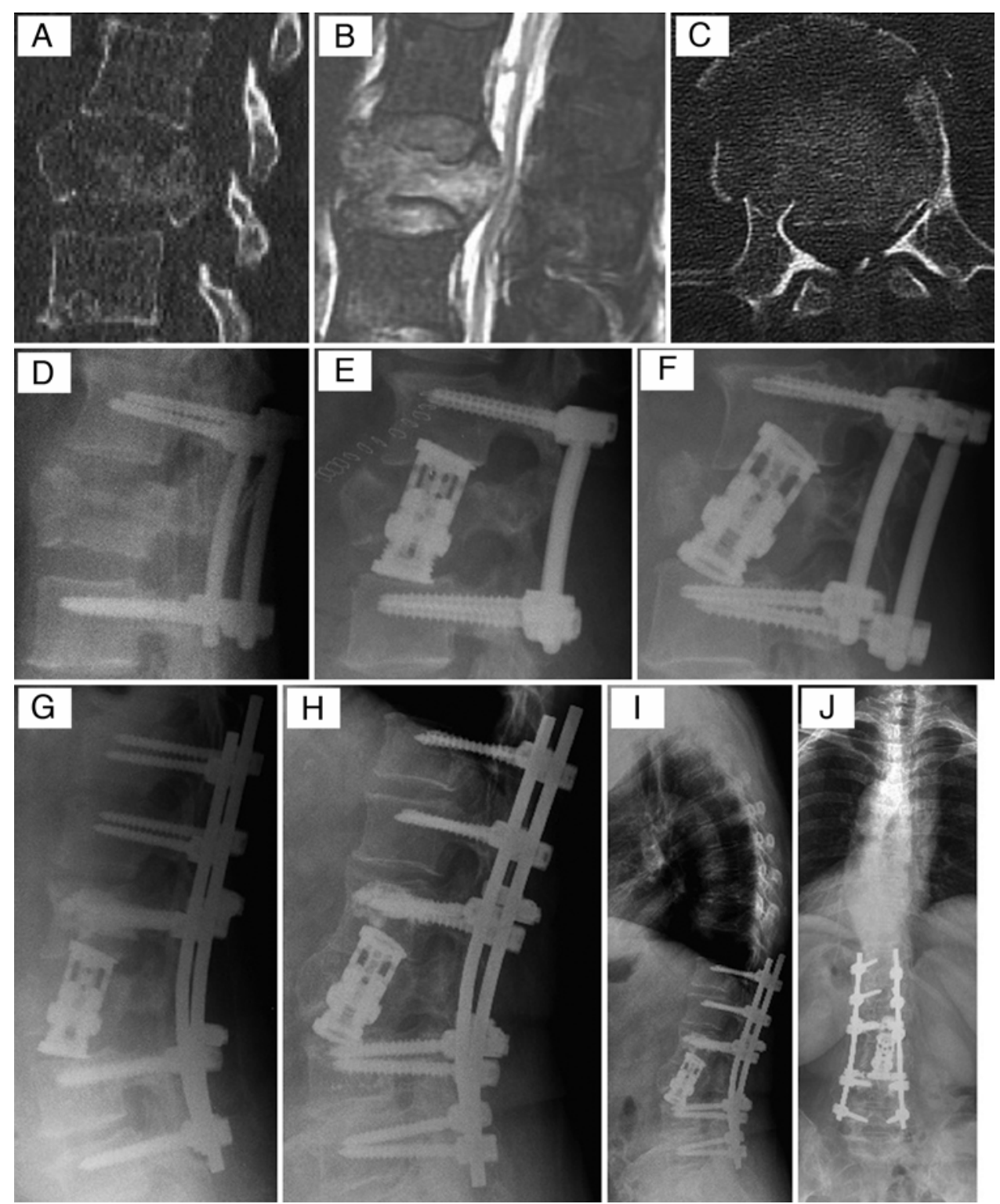

FIG. 1. Case 2. Radiographic images of a 68-year-old woman with osteoporosis who sustained an L-3 burst fracture (A-C) without neurological deficits after falling 13 steps on a stairwell. Her fracture was initially stabilized with short-segment posterior pedicle screws placed percutaneously (D). Two days later, she underwent anterior decompression and stabilization with a cage with traditional "circular" footprints (E). Two weeks postoperatively, cage subsidence with fracture of the upper endplate that resulted in progressive loss of fixation was noted (F). She subsequently underwent T12-L5 posterior spinal fusion with an L-2 kyphoplasty (G). Radiographically, there was adequate sagittal and coronal imbalance with no signs of hardware failure, loss of focal angulation, or cage subsidence after her revision surgery $(\mathrm{H}-\mathrm{J})$.

All 12 patients had preoperative and postoperative radiographs. Average radiographic follow-up was 37 months (range 6-68 months). Radiographic data with respect to focal lordosis and lumbar lordosis are presented in Fig. 3 . The average preoperative focal lordosis was $-12^{\circ}(\mathrm{ky}-$ phosis; range $-25^{\circ}$ [kyphosis] to $+6^{\circ}$ [lordosis]), and the average lumbar lordosis was $39^{\circ}$ (range $10^{\circ}-59^{\circ}$ ). After posterior fixation and anterior column support, average postoperative focal lordosis was $10^{\circ}$ (range $0^{\circ}-16^{\circ}$ ). Average postoperative lumbar lordosis $\left(54^{\circ}\right.$, range $\left.32^{\circ}-74^{\circ}\right)$ was significantly greater than preoperative lumbar lordosis (Fig. 3). At the latest follow-up, lumbar lordosis was $52^{\circ}$ (range $41^{\circ}-72^{\circ}$ ) and focal lordosis was $7^{\circ}$ (range, $6^{\circ}-22^{\circ}$ ) (Fig. 3).

At an average of 38 months (range 16-68 months) of postoperative clinical follow-up, 11 patients were able to be contacted and completed the SF-12, ODI, and scarrelated questionnaire over the phone or in the clinic. One patient did not complete the questionnaires, because she was not content with her care. The average ODI score was $20 \pm 17$ (range $0-52$ ). The average SF-12 PCS was $41.7 \%$ $\pm 10.4 \%$ (range $25.7 \%-55.3 \%$ ) and SF-12 MCS was $50.2 \%$ $\pm 11.6 \%$ (range $30.8 \%-62.6 \%$ ). The average pain score related to the scar was 2.6 (range $0-8 ; 0=$ no pain, 10 

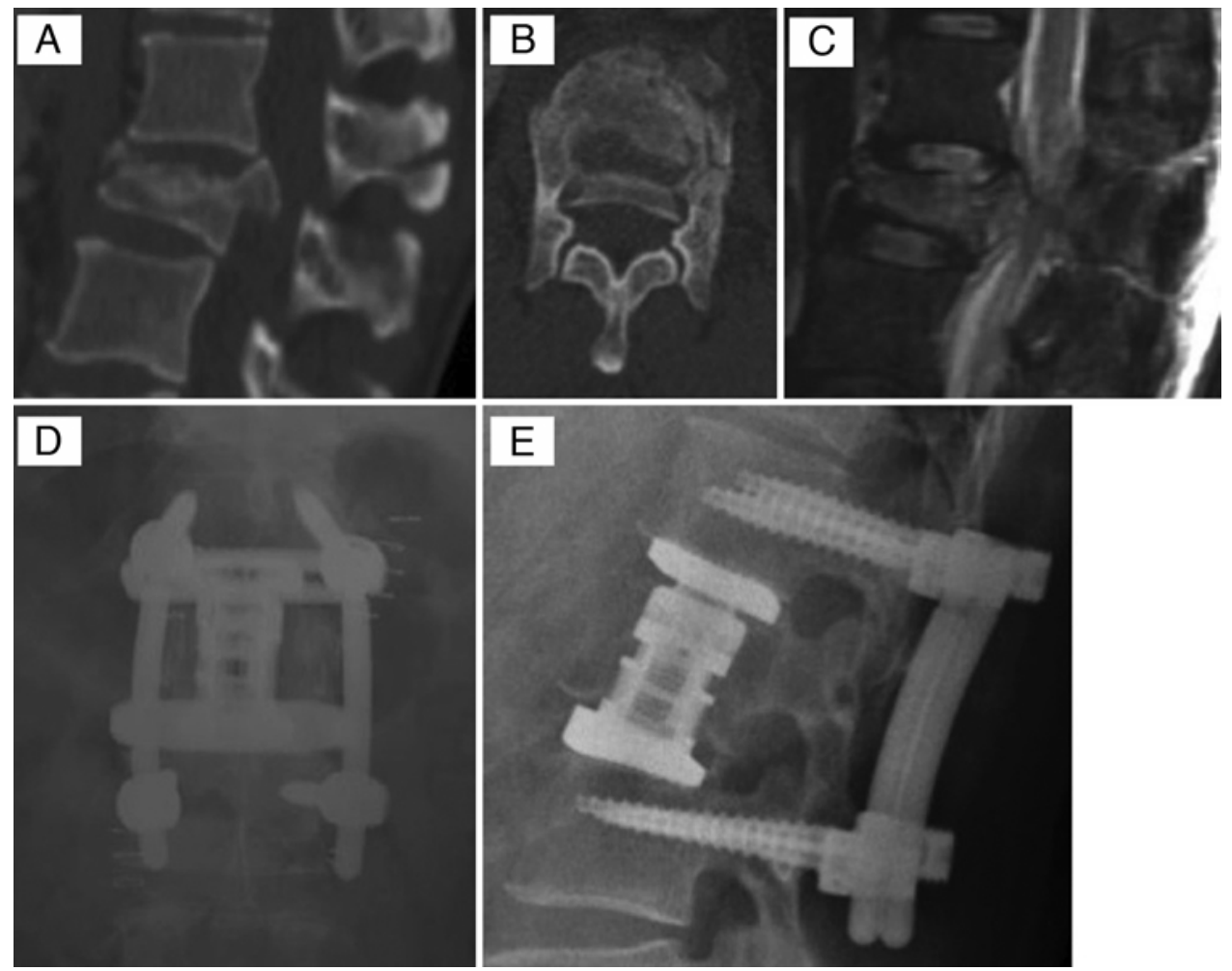

FIG. 2. Case 10. Radiographic images of a 48 -year-old man who sustained an L-1 burst fracture (A-C) without neurological deficits after falling 15 feet. His fracture was stabilized with short-segment posterior pedicle screws placed percutaneously and anterior decompression and stabilization with a cage with a wide "rectangular" footprint ( $D$ and $E)$. The construct showed no signs of hardware failure, loss of focal angulation, or cage subsidence at the 12-month postoperative visit (D and E)

$=$ severe pain). In regards to the frequency of scar-related pain, 6 patients rarely had pain $(<1$ time per month), 4 reported frequent pain (2-3 times per week), and 1 patient reported daily pain. Two patients reported bulging around or over the scar; however, there was no evidence of hernia at the level of the scar or more anterior due to neural injury from the exposure. While $42 \%$ of patients $(n=5)$ reported that the anterior incision limited their ability to do things around the house, no patient reported having any other major problem related to their scar. No patient received any treatment for the scar postoperatively. In regards to selfimage, $91 \%$ of patients $(n=10 / 11)$ reported that they felt they looked the same $(n=2)$, better $(n=6)$, or much better $(\mathrm{n}=2)$ compared with before the surgery in regards to their torso/chest. The average appearance of the scar was rated as 8.4/10. When asked whether they would undergo the same treatment given their current results, $64 \%$ percent of patients answered "definitively yes" and $27 \%$ answered "probably yes." When asked if they could undergo their surgery again and it could be performed all from a posterior approach, 55\% percent of patients answered "definitely yes" and $18 \%$ answered "probably yes."

\section{Discussion}

Minimally invasive surgery (MIS) approaches to the lumbar spine were designed to avoid complications associated with the traditional anterior approach. The concept of MIS continues to evolve, and the true indications for
MIS in the setting of trauma have not been established. ${ }^{17,25}$ Eck was the first to report on the use of an MIS anterior approach for corpectomy combined with posterior stabilization to treat a 30-year-old man with an L-3 burst frac-

TABLE 2. Intraoperative and hospital data for patients with single-level lumbar burst fractures who underwent anterior lumbar corpectomy via a mini-open, extreme lateral, transpsoas approach and short-segment posterior fixation*

\begin{tabular}{lc}
\hline \multicolumn{1}{c}{ Variable } & Average (range) \\
\hline Intraoperative data & \\
\hline Incision length (cm) & $6.4(5-8)$ \\
\hline Length of surgery (mins) & $288.7(205-498) \dagger$ \\
\hline Chest tube placement for pleural injury & 3 \\
\hline Estimated blood loss (ml) & $988(50-3000)$ \\
\hline Hospital data & \\
\hline Length of stay (days) & $18.4(7-47)$ \\
\hline Blood transfusions & 2 \\
\hline Disposition & \\
Home & 5 \\
Skilled nursing facility & 4 \\
Medical respite & 1 \\
Acute care & 2 \\
\hline
\end{tabular}

\footnotetext{
* Excluded level of corpectomy.

$\dagger$ Excluded 2 patients who each underwent concomitant placement of ankle external fixators.
} 


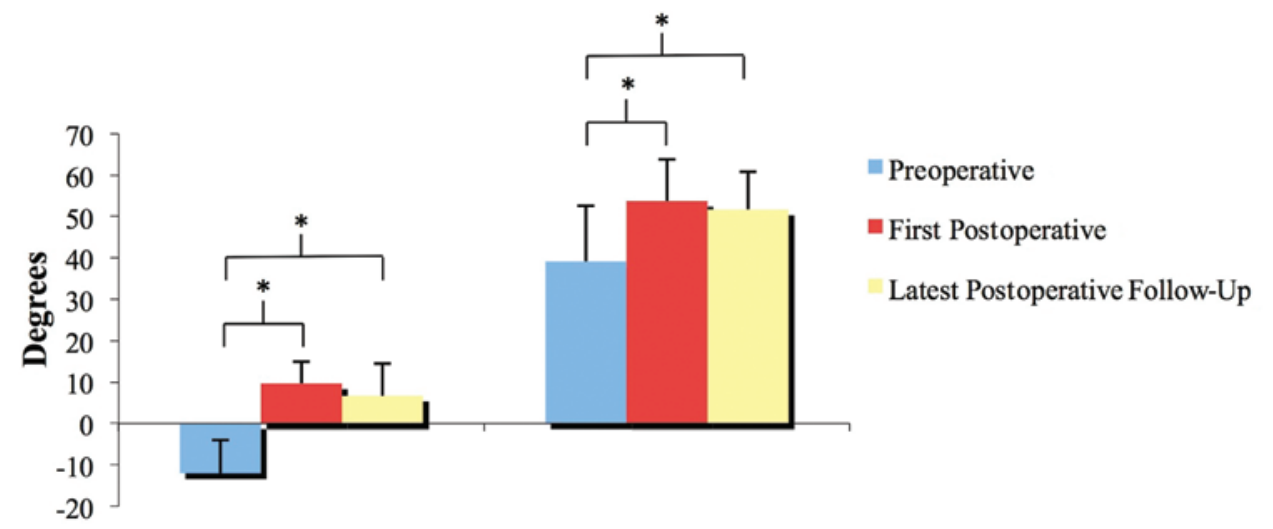

\section{Focal Lordosis $\quad$ Lumbar Lordosis}

FIG. 3. Preoperative, first postoperative, and latest follow-up radiographic values for focal lordosis at the level of injury and lumbar lordosis. Note that a statistically significant difference was observed between the preoperative lumbar lordosis and focal lordosis and respective measurements in the immediate postoperative period and at the latest radiographic follow-up. ${ }^{*} p<0.05$. Figure is available in color online only.

ture after a motor vehicle accident. ${ }^{7}$ The only complication was left leg pain and numbness that resolved after 6 months. ${ }^{7}$ Eck stated that, "benefits of this approach include avoiding the need for retraction of the retroperitoneal vessels and sympathetic plexus, less muscle dissection, and less manipulation of the abdominal contents, and subsequent ileus". 7 Since Eck's original report, several studies have reported good outcomes using the aforementioned "mini-open" lateral approach combined with posterior fixation to perform a corpectomy for burst and compression fractures, vertebral tumors and osteomyelitis, spondylodiscitis, and pseudarthrosis following previous corpectomy. $1,2,6,8,13,16,20,24,27$

Our study presented herein presents a pure clinical series of patients who underwent single-level lumbar corpectomies with cage placement through a mini-open, extreme lateral, transpsoas approach supplemented with shortsegment posterior instrumentation. Direct comparison of operative data and clinical outcomes to previous studies is difficult, as all previous studies include heterogeneous cohorts with regards to spinal level of pathology, disease process, and surgical approach. ${ }^{8,13,16,20,24,26}$ Despite these discrepancies, our results compare favorably with results from previous reports. Our average estimated blood loss and length of operation are longer than that reported in the literature. $7,8,13,24,26$ This may be due to the heterogeneity in individual procedures or the learning curve attributed to a relatively newer surgical technique. Additionally, the average length of hospital stay (18.4 days) for our patients is longer than the previously reported range of 36 hours $^{26}$ to 4 days. ${ }^{24}$ This may be attributable to our patients' associated injuries and complications and/or the socioeconomic status of our patients, many of whom are marginally housed or homeless.

Our overall postoperative complication rate was $25 \%$, with a reoperation rate of $17 \%$. Intraoperative complications attributable to the anterior approach occurred in 25\% of the patients. The reported overall rate of complications for open and MIS anterior approaches for single-level thoracolumbar pathology range from $13.5 \%{ }^{24}$ to $41 \%^{13}$ in the literature. Our complications included wound infections, failure of fixation, and a pulmonary embolism. Pleural injuries occurred when the pleura was dissected from the chest wall, which also occurs during the conventional approach. No neurological complications were noted. Other notable complications reported in the literature for this approach include spleen hemorrhage, paraspinal abscesses, dural tears, intercostal neuralgia, deep venous thrombosis, pleural effusions, infections of the chest, and cage subsidence. ${ }^{8,13,24}$ Our 1 case of graft subsidence and failure requiring revision surgery occurred in an osteoporotic patient who had undergone corpectomy and anterior stabilization with a telescoping cage whose footprint was smaller than adjacent endplates. Smith et al. noted radiographic evidence of cage subsidence in $13.5 \%$ of their 52 patients who had undergone a "mini-open" corpectomy from a lateral approach for unstable thoracolumbar burst fractures (T7-L4). ${ }^{24}$ Interestingly, they noted no cage subsidence in patients treated with expandable wide-footprint titanium cages, and their only revision for cage subsidence occurred in 1 patient who was treated with an expandable cylindrical titanium cage. ${ }^{24}$ We observed a similar phenomenon. Although our study suggests that vertebral interbodies with wider endplates should be considered in the setting where implants have a load-bearing role, the small number of patients treated with each type of cage in this study is a limitation, and future clinical studies should further address this question with larger cohorts of patients.

This study also reports clinical outcomes and satisfaction of patients with unstable burst fractures treated with anterior column support with a cage via a mini-open, extreme lateral, transpsoas approach and short-segment posterior instrumentations. Patients were satisfied with their outcomes, had minimal disability, and had excellent physical and mental health outcomes after surgery. Our patients' average functional disability scores are similar to the disability scores reported in the literature (range 5.5-20.8) for patients treated operatively for burst fractures. $5,11,21,28-30$ Our patients had minimal pain and good aesthetic results associated with their anterior scar, and thus $89 \%$ of patients responded that they would have the same treatment of their spine again given their current re- 
sults. However, $75 \%$ of patients stated that if they could have their surgery performed again they would prefer to have it performed from an all-posterior approach. It is unclear why patients would prefer a posterior-only approach given their lack of dissatisfaction with their anterior scar. However, this patient preference is similar to that reported by Kim et al. of 62 patients with adult deformity treated via an anterior thoracolumbar approach. ${ }^{12}$ There does not appear to be a difference in functional outcomes between patients with burst fractures treated with all posterior constructs and those treated by combined anterior/posterior approaches., ${ }^{41,21,29,30}$ Briem et al. found that patients with burst fractures treated with posterior-only constructs had lower average physical and mental health outcome scores on the 36-Item Short Form Health Survey questionnaire compared with those treated with combined anterior and posterior approaches. ${ }^{4}$ However, Defino et al. found the opposite to be true. ${ }^{5}$ These discrepancies are likely multifactorial, as each trauma patient is heterogeneous with regards to concomitant injuries, initial neurological status, patient expectations, underlying medical and psychological comorbidities, and preinjury functional status. Surgical and medical complications may also play a role in a patient's self-reported outcome.

Our study has limitations. It is retrospective, evaluates a relatively small number of patients, does not directly compare outcomes to traditional open anterior approaches for treatment of unstable burst fractures, and includes a heterogeneous patient population with regards to implant type and clinical and radiographic follow-up. Additionally, CT scans were not obtained on all patients to assess fusion, given concerns of cost and radiation to patients. Future studies should be prospective in nature with larger patient cohorts and more homogeneous patient populations. These studies should also include CT scan assessment of fusion for every patient, as plain radiographs are relatively insensitive for diagnosing pseudarthrosis. These studies should also compare patient-reported outcomes and satisfaction between patients with unstable burst fractures treated with a mini-open, extreme lateral, transpsoas approach, and those with traditional open anterior approaches.

\section{Conclusions}

Single-level lumbar corpectomy with cage placement through a mini-open, extreme lateral, transpsoas approach supplemented with short-segment posterior instrumentation is a safe and effective minimally invasive alternative to standard open, anterior approaches for unstable, traumatic burst fractures. Patients report excellent functional outcomes and satisfaction postoperatively.

\section{References}

1. Adkins DE, Sandhu FA, Voyadzis JM: Minimally invasive lateral approach to the thoracolumbar junction for corpectomy. J Clin Neurosci 20:1289-1294, 2013

2. Amaral R, Marchi L, Oliveira L, Coutinho T, Pimenta L: Acute lumbar burst fracture treated by minimally invasive lateral corpectomy. Case Rep Orthop 2013:953897, 2013

3. Aydinli U, Karaeminoğullari O, Tişkaya K, Oztürk C: Dural tears in lumbar burst fractures with greenstick lamina fractures. Spine (Phila Pa 1976) 26:E410-E415, 2001
4. Briem D, Behechtnejad A, Ouchmaev A, Morfeld M, Schermelleh-Engel K, Amling M, et al: Pain regulation and healthrelated quality of life after thoracolumbar fractures of the spine. Eur Spine J 16:1925-1933, 2007

5. Defino HL, Herrero CF, Romeiro CF: Monosegmental fixation for the treatment of fractures of the thoracolumbar spine. Indian J Orthop 41:337-345, 2007

6. Dhall SS, Wadhwa R, Wang MY, Tien-Smith A, Mummaneni PV: Traumatic thoracolumbar spinal injury: an algorithm for minimally invasive surgical management. Neurosurg Focus 37(1):E9, 2014

7. Eck JC: Minimally invasive corpectomy and posterior stabilization for lumbar burst fracture. Spine J 11:904-908, 2011

8. El Saghir H: Extracoelomic mini approach for anterior reconstructive surgery of the thoracolumbar area. Neurosurgery 51 (5 Suppl):S118-S122, 2002

9. Fairbank JC, Pynsent PB: The Oswestry Disability Index. Spine (Phila Pa 1976) 25:2940-2952, 2000

10. Isaacs RE, Hyde J, Goodrich JA, Rodgers WB, Phillips FM: A prospective, nonrandomized, multicenter evaluation of extreme lateral interbody fusion for the treatment of adult degenerative scoliosis: perioperative outcomes and complications. Spine (Phila Pa 1976) 35 (26 Suppl):S322-S330, 2010

11. Jonathan-James TE, Chen JL, Mitsunaga MM: Short samesegment fixation of thoracolumbar burst fractures. Spine J 10:S109, 2010

12. Kim YB, Lenke LG, Kim YJ, Kim YW, Blanke K, Stobbs G, et al: The morbidity of an anterior thoracolumbar approach: adult spinal deformity patients with greater than five-year follow-up. Spine (Phila Pa 1976) 34:822-826, 2009

13. Lu DC, Lau D, Lee JG, Chou D: The transpedicular approach compared with the anterior approach: an analysis of 80 thoracolumbar corpectomies. J Neurosurg Spine 12:583-591, 2010

14. McCormack T, Karaikovic E, Gaines RW: The load sharing classification of spine fractures. Spine (Phila Pa 1976) 19:1741-1744, 1994

15. Mehta JS, Reed MR, McVie JL, Sanderson PL: Weight-bearing radiographs in thoracolumbar fractures: do they influence management? Spine (Phila Pa 1976) 29:564-567, 2004

16. Muhlbauer M, Pfisterer W, Eyb R, Knosp E: Minimally invasive retroperitoneal approach for lumbar corpectomy and reconstruction. Technical note. Neurosurg Focus 7(6):e4, 1999

17. Ni WF, Huang YX, Chi YL, Xu HZ, Lin Y, Wang XY, et al: Percutaneous pedicle screw fixation for neurologic intact thoracolumbar burst fractures. J Spinal Disord Tech 23:530-537, 2010

18. Ozgur BM, Aryan HE, Pimenta L, Taylor WR: Extreme Lateral Interbody Fusion (XLIF): a novel surgical technique for anterior lumbar interbody fusion. Spine J 6:435-443, 2006

19. Ozturk C, Ersozlu S, Aydinli U: Importance of greenstick lamina fractures in low lumbar burst fractures. Int Orthop 30:295-298, 2006

20. Payer M, Sottas C: Mini-open anterior approach for corpectomy in the thoracolumbar spine. Surg Neurol 69:25-32, 2008

21. Pfeifer R, Pishnamaz M, Dombroski D, Heussen N, Pape HC, Schmidt-Rohlfing B: Outcome after thoracoscopic ventral stabilisation of thoracic and lumbar spine fractures. J Trauma Manag Outcomes 6:10, 2012

22. Riddle DL, Lee KT, Stratford PW: Use of SF-36 and SF-12 health status measures: a quantitative comparison for groups versus individual patients. Med Care 39:867-878, 2001

23. Rodgers WB, Gerber EJ, Patterson J: Intraoperative and early postoperative complications in extreme lateral interbody fusion: an analysis of 600 cases. Spine (Phila Pa 1976) 36:2632,2011

24. Smith WD, Dakwar E, Le TV, Christian G, Serrano S, Uribe 
JS: Minimally invasive surgery for traumatic spinal pathologies: a mini-open, lateral approach in the thoracic and lumbar spine. Spine (Phila Pa 1976) 35 (26 Suppl):S338-S346, 2010

25. Smith ZA, Li Z, Chen NF, Raphael D, Khoo LT: Minimally invasive lateral extracavitary corpectomy: cadaveric evaluation model and report of 3 clinical cases. J Neurosurg Spine 16:463-470, 2012

26. Tomycz L, Parker SL, McGirt MJ: Minimally invasive transpsoas L2 corpectomy and percutaneous pedicle screw fixation for osteoporotic burst fracture in the elderly. J Spinal Disord Tech 28:56-30, 2015

27. Tomycz ND, Chew BG, Chang YF, Darby JM, Gunn SR, Nicholas DH, et al: MRI is unnecessary to clear the cervical spine in obtunded/comatose trauma patients: the four-year experience of a level I trauma center. J Trauma 64:12581263,2008

28. Wood K, Buttermann G, Mehbod A, Garvey T, Jhanjee R, Sechriest V: Operative compared with nonoperative treatment of a thoracolumbar burst fracture without neurological deficit. A prospective, randomized study. J Bone Joint Surg Am 85-A:773-781, 2003 (Erratum in J Bone Joint Surg Am 86-A:1283, 2004)

29. Yang H, Shi JH, Ebraheim M, Liu X, Konrad J, Husain I, et al: Outcome of thoracolumbar burst fractures treated with indirect reduction and fixation without fusion. Eur Spine J 20:380-386, 2011

30. Yaray O, Akesen B, Aydinli U: Long-term outcome after surgical treatment of thoracolumbar fractures versus a control group of healthy volunteers. Acta Orthop Belg 77:93-96, 2011

\section{Disclosure}

No funds were received in support of this work. A family member of Abbey Kennedy, MD, is an employee of Stryker Spine Division. R. Trigg McClellan, MD, receives grant support from Stryker and NuVasive. Murat Pekmezci, MD, receives grant support from $\mathrm{NuVasive}$ for a separate study and has a nonfinancial relationship with Stryker, which provides grant funds directly to the institution for a separate study. Other financial activities outside the submitted work include: expert testimony, grants, consultant, patents, and stock options.

\section{Author Contributions}

Conception and design: McClellan, Pekmezci. Acquisition of data: Theologis, Tabaraee, Kennedy, Birk. Analysis and interpretation of data: Theologis, Tabaraee, Kennedy, Birk, McClellan, Pekmezci. Drafting the article: Theologis, Tabaraee, Toogood, Kennedy, Birk. Critically revising the article: all authors.

Reviewed submitted version of manuscript: all authors. Approved the final version of the manuscript on behalf of all authors: Theologis. Statistical analysis: Theologis. Administrative/technical/ material support: Theologis, McClellan, Pekmezci. Study supervision: McClellan, Pekmezci.

\section{Correspondence}

Alexander A. Theologis, Department of Orthopaedic Surgery, University of California, San Francisco, 500 Parnassus Ave., MUW 320, San Francisco, CA 94143.email: alekos.theologis@ ucsf.edu. 